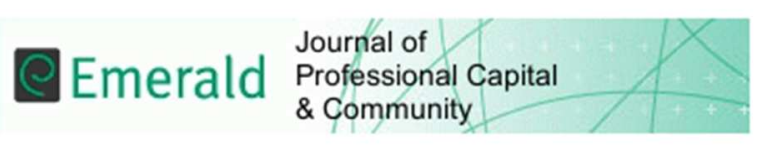

\title{
Inspiring teaching: learning from exemplary practitioners
}

\begin{tabular}{|r|l|}
\hline Journal: & Journal of Professional Capital \& Community \\
\hline Manuscript ID & JPCC-09-2015-0005.R2 \\
\hline Manuscript Type: & Research Paper \\
\hline Keywords: & Leadership, Professional Development, Professional Learning Community \\
\hline \multicolumn{2}{|l}{} \\
\hline
\end{tabular}

SCHOLARONE $^{\text {m }}$

Manuscripts 


\section{Structured Abstract}

\section{Purpose}

An investigation of the concept of ' inspiring teaching' based on case studies of exemplary practitioners in England to inform professional development and collaborative learning and support school improvement.

\section{Design /methodology/approach}

The study adopted a mixed methods design involving multiple perspectives. Data sources included interviews with teachers, two systematic classroom observation schedules and qualitative field notes from classroom observations. Quantitative and qualitative findings were integrated to allow for triangulation and synthesis.

\section{Findings}

The 'inspiring' sample of teachers exhibited many strengths in terms of the characteristics of more effective teaching identified in previous literature. However, the integration and synthesis of evidence also reveals core features of inspiring practice and highlighted the strong emotional and reflective components that distinguish inspiring practice:

- positive relationships

- good classroom/behaviour management

- positive and supportive climate

- formative feedback

- high quality learning experiences

- enjoyment

- high levels of student engagement and motivation.

\section{Research limitations/implications}

This small-scale study was based on a purposive sample of 17 teachers in England therefore results cannot necessarily be generalised to other contexts.

\section{Practical implications}

The research findings and approaches can be used to support teachers' professional development and provide resources to promote collaboration in developing professional learning communities.

\section{Originality/value}

The investigation provides new evidence on the characteristics, practices and views of inspiring teachers. The use of multiple perspectives and integration of findings provides new evidence to inform and support the development of professional learning communities.

Title: 


\section{Inspiring teaching: learning from exemplary practitioners}

\section{Introduction}

This paper draws on research conducted for the 'Inspiring teachers' study (Sammons et al, 2014) and explores its implications for professional development and the creation of communities of practice in schools. The 'Inspiring teachers' research sought to investigate the increasingly used but generally poorly defined notion of 'inspiring teaching' through case studies of a purposive sample of 17 primary and secondary school teachers in England conducted during 2013. It was commissioned by CfBT Education Trust, a non-profit charity, as part of a collaborative professional development initiative involving its schools. It arose from head teachers' interest in learning more about inspiring teaching, to improve practice and promote improvement. Head teachers nominated individual teachers to take part in a voluntary, mixed methods study with results to be shared across participating schools to spread good practice by encouraging greater collaboration. Teachers were identified as exemplars that demonstrated qualities and practices viewed as 'inspiring' by colleagues and students. Exploring their practices and perspectives has generated valuable insights with implications for professional development and learning communities.

\section{Definitions of inspiring teaching}

The Oxford Encyclopedic English dictionary definition of 'inspire' refers to the ability to 'stimulate' or 'arouse' as well as to 'encourage' others. It also notes links with 'creativity'. The Latin origins suggest the action of filling or inflaming associated with divine inspiration. In the more modern context of organizational studies, Gilson and colleagues (2001) have analysed 'Peak Performance' and drawn attention to the role of inspirational players in sports team and the implications for those seeking to create highly effective organisations. They note that real success is a continuous process rather than a static state and argue that 'most learn to become inspirational players in organisational life' ( $p 7$ ).

The words 'inspiring' and 'inspirational' are not new to the field of education, but have come into more frequent use in recent education policy. The language of the Teachers' Standards published by the Department for Education (DfE) in England reflects this, stating that teachers must, among other things, "inspire, motivate, and challenge pupils" (DfE, 2013, p.7), while reports by the influential Office for Standards in Education (Ofsted), the national inspection agency, show increasing use of the words 'inspiring' or 'inspirational' to describe teaching, learning environments and leadership in outstanding schools (e.g. Ofsted, 2011). Interest in the notion of 'inspiring practice' is also evident in OECD publications (OECD, 2013) and policy documents by various national and federal governments (e.g. PCAST, 2010).

The same terminology has also come into vogue in literature aimed at practitioners. Many handbooks offer advice, guidance and practical exercises for inspiring teaching, largely based on authors' personal experiences and similar anecdotal evidence, though differing as to what inspiring teaching means or what inspiring teachers do, ranging from specific practices to long-term impact on students' lives (e.g. Erwin, 2010; McGuey \& Moore, 2007). A growing number of newspaper, magazine and journal articles also aim to either describe or prescribe inspiring teaching practices. The bulk of these include profiles of teachers identified as inspiring, often drawing on the practice of one or several teachers, or on personal experience, to suggest criteria for cultivating inspiring practice (Collins, 2006; Richards, 2004).

Some prevalent themes are apparent across the literature:

- inspiring teaching is frequently described as exciting, innovative and/or creative 
- evidence of inspiration is framed in various ways, usually one or more of the following: immediate student engagement in the classroom, a lasting effect on students' aspirations and self-concepts, or their interest in a particular subject

- descriptions of specific practices that might be more usually linked to notions of 'effective' practice.

The first of these hints at a partial definition of inspiring teaching as it is often intuitively understood. The second introduces a definitional challenge, as it is necessary to define what is meant by inspiration before attempting to measure it and investigate how it may be engendered. The third makes connections with another important concept for teachers, that of effectiveness (an aspect discussed later in this paper).

In the empirical literature, some operational definitions implicitly link inspiration to outcomes of student engagement (Bryson \& Hand, 2007) and motivation (Bowman, 2007). This accords with the dictionary origins of the term, being aligned with the concept of 'stimulating influence' coined by van der Zee (2011) in a study of RE teachers that named student outcomes of inspiring teaching as "social virtues, knowledge, insight, spirituality and a sense of transcendence" (p.21). Hobbs's (2012) small-scale study introduces teacher attributes, particularly teacher knowledge, identity, and passion, that resonate with themes emerging from the non-empirical literature.

Bryan, Glynn, and Kittleson's (2011) study of secondary science students also assessed motivation but, in addition, included students' self-efficacy and self-determination as outcomes, finding all three were related to achievement. They identified inspiring teachers as strong motivators for future science students' aspirations, going beyond links with current effort or engagement. Santolini's (2009) study of motivations to enter the profession also offers a possible understanding of what it means to be inspired, indicating that participants' experiences with inspiring teachers when they were in school affected subsequent career choices and trajectories. Burke \& Nierenberg (1998) examined pre-service teachers' perceptions, finding that inspiring teachers were characterized in socio-emotional terms as dedicated, positive, and caring.

While such studies show some overlap in their definitions of inspiring teaching and its outcomes, there remains an overall lack of clarity and agreement. Drawing together the definitions and outcomes used explicitly and implicitly in existing literature suggests a framework for understanding inspiring teaching hinging on the following:

- positive student outcomes (e.g. motivation, self-efficacy, aspiration, achievement; both long and short term effects),

- particular teacher behaviours and practices,

- teacher characteristics (e.g. personality traits, knowledge, and motivation) and relationships.

There is an important distinction between inspiring and effective teaching from the perspective of measurement and evaluation. Much research has been conducted to investigate effective classroom practice, demonstrated by recent reviews (e.g. Muijs et al., 2014). While there is a strong tradition for judgments of effective teaching to be based on students' academic outcomes, the word 'inspiring' casts a wider net linking with affective and social-behavioural outcomes. This raises questions about the extent to which inspirational outcomes overlap with effective outcomes, and whether effectiveness is compatible with, part of, or different from inspiring practice.

Another gap in the empirical literature concerns theory and methodology. The studies described above rely primarily on attitudinal measures, interviews, and similar indirect measures. What is missing, then, is direct observation and measurement. The Inspiring teachers research drawn on in this paper addressed this by using mixed methods including direct observations. 
The empirical literature on inspirational teaching largely focuses on individual practice, making little mention of professional development. Further, the potential of inspiring practitioners to play a role in shaping professional culture in schools merits further exploration. While the present study focuses on individual teachers, it considers teachers' broader roles within their schools, and part of its underlying purpose was to inform professional development and act as a resource to promote professional learning communities. The concluding section will discuss how the Inspiring teachers research adds to the existing literature and explores implications for professional practice and learning communities.

\section{Aims}

The Inspiring Teachers study (Sammons et al, 2014) sought to learn more about the characteristics and practices of exemplary teachers, understand how they had grown professionally, and make findings available to support school improvement across the CfBT School Trust(CST). This article addresses two research questions and explores their implications for professional development and school learning communities:

- What do inspiring teachers say about their practice?

- What do inspiring teachers do in their classrooms?

\section{Methods}

Information was obtained from 17 teachers (7 primary, 11 secondary), working in nine schools. The schools covered a range of contexts (urban/rural and different levels of socio-economic disadvantage of student intakes).

Primary teachers taught all subjects in general primary education. At the secondary level, subject specialisms included English, mathematics, history, geography, modern foreign languages, art and physical education. The year groups taught by participants ranged from Nursery (age 4+) to Year 12 (age 17+). Most were early- or mid-career teachers and had worked in more than one school. More than half held additional responsibilities or leadership positions in their schools.

The majority of instruments used had been generated and/or validated in the English context in previous published work investigating classroom practice (Day et al., 2007; Kington et al., 2014; Sammons et al., 2007). However, additional items and interview questions provided further evidence on 'inspiring teaching' and 'inspiring teachers' to explore the practices and individual characteristics associated with the concept. Qualitative and quantitative sources included:

- Semi -structured Interviews -Topics explored included descriptions of each teacher's practice, discussion of inspiring teachers encountered in each teacher's academic/professional career, interpretation of inspiring teaching, factors affecting practice, current job satisfaction, motivation, commitment, and career plans.

- Systematic classroom observations - Two instruments were used: the International System of Teacher Observation and Feedback (ISTOF) (Teddlie et al., 2006) and the Lesson Observation Form for Evaluating the Quality of Teaching (QoT) (van de Grift, 2007). The former was developed by researchers drawing on research evidence and expert opinions from 19 countries. The latter was research-based, but was additionally influenced by inspection approaches in the Netherlands and England. A total of 28 lessons were observed (11 teachers in two lessons, 6 in one lesson).

- Classroom observation notes -These included details on the structure, organization, and flow of the lesson, nature of lesson activities, interactions between students and teachers, 
classroom climate, teachers' personas, and vignettes of notable features/examples of practice.

Qualitative analysis included thematic analysis in NVivo (QSR International, 2012) of transcripts and observation notes. Teacher attributes were incorporated to explore patterns by school sector, career phase, and gender. Quantitative analysis was carried out in SPSS (IBM Corp., 2012). For the systematic observation data, inter-rater reliability was assessed using AgreeStat (Advanced Analytics, 2011).

Initial organizational themes for the qualitative coding were compared to quantitative items from the observation schedules; qualitative analysis also involved various amounts of 'quantizing' (e.g. ordering of codes and themes according to percent source coverage, or frequency calculations). Quantitative data were also 'qualitized' by identifying a discrete set of dimensions or components that could be compared to the qualitative themes for triangulation, and used to explore how the qualitative findings helped to extend or elaborate upon aspects of quantitative findings.

\section{Findings}

Interviews probed teachers' understandings and definitions of inspiring teaching. They also provided teachers an opportunity to talk about their work and schools. The sample showed considerable ability to reflect on their practice and their roles and work in schools, suggesting that being a reflective practitioner is a strong component of inspiring practice.

Participants identified the main characteristics of inspiring teachers as:

- Having and transmitting enthusiasm

- Cultivating positive relationship with students

- Making learning purposeful and relevant for students

- Being flexible and adapting their practice

- Promoting a safe and stimulating classroom climate

- Establishing clear and positive classroom management

- Being reflective about their own practice and developing collaboratively

- Bringing innovation to the classroom.

The following quote illustrates how key phrases were coded (bold text) and vividly highlights the combination of personal and professional attributes to which teachers alluded.

"Number one for me is a passion for their career. I think there is a slight bit of madness to it, you have to be little bit crazy and a little bit different and I don't think you can inspire others to learn if you're not willing to learn as well. Creativity, imagination and, yes, there has to be an element of fun, you need to be relaxed, you need to be confident, and you need to have a mutual respect between yourself and your pupils, and your learning environment has to be in such a way that children feel that they can take risks and that it's absolutely fine to do that. There has to be discipline, there has to be rules, there has to be procedure, and there has to be an element of fairness and children have to be treated the same way and no one should ever feel as they are not a favourite, because every child is a favourite". (Female, Primary, 16-20 Years of experience (YOE))

Two characteristics most frequently mentioned were Enthusiasm for teaching (cited by 14), and Positive relationships with students (11). These two main features are followed by other commonly identified themes including: Positive classroom management, Reflectiveness and collaboration, Purposeful and relevant teaching, Contextual factors, Collaboration and CPD, Flexibility, Safe and stimulating classroom climate, and Innovative Teaching. 


\section{Enthusiasm for teaching}

According to interviewees, the defining characteristic is having a passion for the profession.

"I put enthusiasm as one of the top, because I do genuinely think if you're enthusiastic about your job, that means that your whole profession will become better (...) You've got to love what you do, and if you don't like what you do, you're probably not going to be good at it, it's that type of thing'. (Male, Secondary, 6-10 YoE)

These teachers recognised that inspiring teachers could ignite the flame of enthusiasm for students by sharing their own enthusiasm, either for learning or for a particular subject. This, teachers stressed, is closely associated with creating a stimulating learning climate, reflecting on students' experiences and making lessons enjoyable.

"I think for me it's the way they get children excited about learning. It's about taking something that, actually let's face it, maybe isn't that interesting to children, and making it something that they desperately want to do". (Female, Primary, 0-5 YoE)

"I try to sort of reflect that in: 'if I were in my lesson, what would I like to be doing?' and I think they appreciate it and they see fun and enjoyment in that".'(Male, Secondary , 0-5 YoE)

Making learning enjoyable was emphasised by practitioners across school sectors, gender and career phase. In relation to their own teaching, the majority of interviewees saw themselves as naturally enthusiastic and positive, suggesting this may be a personality trait, but they had also intentionally developed their abilities to motivate students.

\section{Positive relationships}

Participants prioritised building and maintaining positive relationships with students; again this did not differ by gender, school sector or career phase. Creating positive relationships seemed central to these teachers' self-efficacy, and was also something that they recognised in examples of teachers who had inspired them in the past and influenced their decision to enter the profession. They were all very confident in their capacity to develop positive but appropriate relationships with their students while maintaining boundaries (e.g. two mentioned not using social media with students).

The key to positive relationships involved getting to know individual students as learners and being aware of their family situations and social contexts. Part of the joy of teaching for these interviewees was the privilege of getting to know students as unique individuals, and this was seen as a two way process.

It's nice to have that, you know, they see you as a person not just a teacher, they do. You have to share a bit of yourself with them and they give back a bit to you, and that sort of builds a good relationship." (Female, Primary, 11-15 YoE)

Participants stressed that relationships with students are dynamic, and they require both effort and time, with consistency in the teachers' behaviour and attitude supporting the development of positive relationships.

Selected examples illustrate the need to get to know students well in order to understand them, to support their learning and engender the desire to learn. A few teachers (4) explicitly linked their understanding of students with the notion of respect, and eight highlighted the value of humour, again linking this with the idea of making learning enjoyable and responding to individual needs. 
"I think I do develop good relationships one-to-one with pupils and I do try to really understand each individual's needs and what they need from me in order to be the best they can be (Female, Secondary, 11-15 YoE)

"I think respect, understanding of children, and by that I mean understanding that they are very intelligent emotionally. I think those factors will influence how well children learn, I think that inspires them to learn ..... you've got to get them to want to learn from you, haven't you?"(Female, Primary, 0-5 YoE)

"I still love that every new child you have, expands that relationship, and getting to know them, and to know what's special about them .... inspiring teachers must have great relationships with their children, and they must understand their children, and be able to respond to their children's needs." (Female, Primary, 16-20 YoE).

All but one expressed a genuine liking for the job and all claimed they liked their students. They believed their students recognised and appreciated that their teachers enjoyed working with them.

"I've been lucky enough that, well, I do this job because I like children and I think children then pick up on the fact that I like them .... They know that I do it because I like spending time with them, so they respond accordingly".(Female, Secondary, 6-10 YoE)

Overall, teachers were confident in their abilities to develop and maintain positive relationships with their students, and accorded this high priority in their practice. Creating positive relationships thus seems to be a driver of their sense of self-efficacy and ability to teach well.

\section{Positive classroom management}

Most (12) teachers referred to positive classroom management (having good control of the class, being fair, firm and consistent), linked to the theme of positive relationships but distinct in its own right, as an essential foundation for inspiring teaching. Teachers argued that good classroom management supported clear academic and behavioural expectations and consistency across the school, and was necessary to highlight the concept of 'fairness' across students. They believed having good classroom control required the right balance between firmness and friendliness. This connects to features of effective teaching (discussed further in relation to the observation data below). The need for clear consistent, boundaries was linked with gaining students' respect.

"[...] you need to have control of your class. If you haven't got control, then you'll never be an inspiring teacher ..... Unless you've got that, then you can't teach anything".(Male, Secondary, 6-10 YoE)

"I think I've seen lots of different teaching styles, and...the teachers that are too firm and too strict, they don't build a rapport, but the teachers who are too relaxed, and too friendly, get taken advantage...They take the mickey, because kids need structure, and they need boundaries. They respect you more .... and they know where they stand".(Female, Secondary, 11-15 YoE)

\section{Reflectiveness and Collaboration}

Ten of the participants made clear that they felt inspiring teachers are consciously reflective about their practice and constantly look for ways to develop their practice further. Reflection was seen as a pre-requisite for both effective and inspiring teaching. 
"I think it had got to be someone who's...for me, the key is to be continually reflective, continually being driven and determined, you know, being reflective and continuing to have that hard work and determination, that encompasses everything else, because it makes sure that your behaviour management is good, it makes sure that your pedagogy is okay, and I think if you continue to do those things, then, that hopefully ensures that your practice is at a high standard". (Female, Secondary, 6-10 YoE)

Participants also stressed that it was important to engage in collaborative reflection with other teachers, thus contributing to the professional development of colleagues, as well as their own learning. Over half the sample were in leadership roles (e.g head of department) that strongly shaped this emphasis.

"It's also your ability to work with the members of staff, because it's okay to be inspiring in your own classroom (...), but actually, inspiring teachers also go and share their ideas and their work, and I feel that's really important". (Female, Secondary, 6-10 YoE)

\section{Purposeful and relevant teaching}

Many (9) teachers stressed the connection between inspiring teaching and relating learning experiences to students' own lives, making learning purposeful, relevant and meaningful.

"Being inspiring to me it's also making it purposeful, you know, if the children are just doing it for the sake of it, well, what's the point? Are they really going to get anything else out of it? Are they going to be inspired to carry on?"(Female, Primary, 6-10 YoE)

These teachers typically felt confident that they could make their teaching relevant to students' lives, linking this with student engagement.

"I think as long as you ensure that the children are understanding things, and they see the relevance of it to their lives, and they see that you've got some passion and enthusiasm and you want to be there, I think that in itself keeps the children in the classroom and inspires them".(Female, Secondary, 0-5 YoE)

\section{Contextual factors}

The inspiring teachers drew attention to the importance of their school working contexts, especially the role of colleagues and senior leaders that affected their professional lives and success in the classroom. They provided examples of contextual features linked with their job satisfaction and motivation. In particular, all teachers stressed the negative impact of contemporary pressures and changes in external policy agendas, especially those related to curriculum and assessment changes and accountability pressures. On the other hand, they stressed the importance of a positive school ethos and the value of support from school leaders and colleagues that they reported fostered their ability to inspire students and promote learning. These exemplary teachers were strongly connected to their school communities. They were not just talented individual teachers, they enjoyed and actively sought out opportunities for collaborating with colleagues, often initiating these themselves.

Support from senior and middle leadership was the most frequently mentioned school factor affecting teachers' practice. Over half explicitly drew attention to this, indicating that they greatly valued leadership that was approachable and participatory. They believed school leaders should set clear, aspirational but realistic expectations for teachers, and provide relevant, constructive 
feedback. They remained strongly committed to improving their own practice and enhancing teaching and learning in their schools or subject departments.

The evidence from the interviews reveals that being effective and inspirational is shaped by features of schools in which teachers worked. Feeling supported was closely linked to motivation, satisfaction and perceived self-efficacy.

\section{Collaboration and CPD}

Teachers placed strong emphasis on the benefits of collaborative professional development with colleagues. Teachers also linked this sense of enthusiasm and passion for the profession with proactively seeking opportunities for professional development and improvement, with around half (8) highlighting they did research and sought feedback from colleagues. The following comment articulates the way enthusiasm drives such activity.

"So yeah, if you've got real enthusiasm to do a bit of research, to go out there and sort of see how other people do stuff, and then take things on board, and be available to, you know, hear feedback, then yeah, that's going to do it, I think, yeah, so I'm going to say enthusiasm". (Male, Secondary, 6-10 YoE)

The degree to which their school's ethos promoted positive and collaborative relationships across teachers was also noted (8). Participants stressed that an important aspect of inspiring teachers' ability to reflect on their practice was to be able to do it collaboratively, and thus contribute to professional development of their teams:

"It's also your ability to work with the members of staff, because it's okay to be inspiring in your own classroom (...), but actually, inspiring teachers also go and share their ideas and their work, and I feel that's really important". (Female, Secondary, 6-10 YoE)

Most teachers reported that their school had some type of professional development programme in place (breakfast training sessions, inset days, etc.). A few teachers (4) explicitly cited collaborative and personalised learning with colleagues in their schools as the most productive and preferred form of professional development.

Teachers were also asked about their professional development needs. The areas that they identified were highly diverse, but the most common were:

- $\quad$ subject knowledge

- differentiation (individualised approaches)

- IT skills.

Various pedagogical skills were also highlighted for development including: planning lessons effectively, assessment practices, outdoor learning, accessing new resources, classroom management, homework monitoring, questioning, marking and student-led learning.

Interview evidence indicates that these teachers were highly proactive in managing their professional development, participating actively in their school and broader professional communities (e.g. social networks/online forums to find and share new ideas to improve their practice).

\section{Flexibility}


Around a third (6) highlighted being flexible and adapting teaching to meet learners' needs.

"I think inspiring teaching is about targeting the right sort of lesson for the right sort of student".((Female, Secondary, 6-10 YoE)

Secondary teachers spoke more explicitly than primary teachers about the need to adapt instruction to support individual students. These teachers considered adaptability vital, allowing plans to change during a lesson depending on the needs or interests of the class and so promoting student engagement and learning.

"If they're not getting anything from it, if they're not learning, or if they're not engaged with something, you might as well stop and try something new. Or ask them, like sometimes I'll stop and I'll say, this isn't working for you, is it? And I'm not telling them off, it's just that it isn' ..... So I'll say okay, well...let's try it this way then... would that be better? And then it's almost like they engage more, because they kind of planned their lesson. And you can still use a lot of the resources that you've got, it's just in a different way". (Male, Secondary, 0-5 YoE)

\section{Safe and stimulating classroom climate}

Five teachers noted the way inspiring teachers create positive learning climates for students, encouraging an open and trusting environment where students feel happy, confident, calm, relaxed and safe. This again emphasises the socio-emotional component of inspiring teaching combined with careful selection and planning of activities.

"I've very rarely seen a good lesson that I thought was inspiring that it had just been down to the activities. It's more down to the response and the introduction of them and the kind of atmosphere they created".(Female, Secondary, 6-10 YoE)

\section{Innovative teaching}

A minority (5) suggested that inspiring teachers, besides being knowledgeable, also bring innovation into their practice and use new, modern approaches to teaching. They exploit their creativity and are willing to take risks. This approach was felt to be associated with using a rich variety of instructional activities to create stimulating lessons.

"This [inspiring] teacher usually had a knowledge and an understanding, and a desire to trial new and modern methods"(Female, Secondary, 6-10 YoE)

"Sometimes it works, sometimes it doesn't, and I think, you know, no matter what stage you're at in your career you should still be doing those things, like taking a risk, not going straight for the things that are easy, or that they know". (Male, Secondary, 0-5 YoE)

"I use my initiative quite a lot I believe to find things out that the children need or that we need to know".(Female, Primary, 0-5 YoE)

Nearly all (15) indicated the need for variety and active learning, both to characterise inspiring teachers generally and to describe their own practice (something observed frequently in their lessons). Again this linked with promoting student enjoyment and engagement.

"It tends to be a bit more active, I think, because they enjoy that more... But I think it's very important to get a real mix of different types of lessons in there". (Male, Secondary, 0-5 YoE) 


\section{Influences on becoming a teacher}

Teachers' reasons for entering the profession varied, but in terms of the timing of their entry into teaching, there were three general pathways identified amongst participants. Some (7) were attracted to teaching from a very young age, knew they wanted to work with children/ young people, and had a strong sense of vocation. Another group (7) indicated they only considered becoming teachers after their university degrees; they had a strong interest in their subjects but found that they enjoyed teaching. A third smaller group (3) were career changers, coming to teaching from a different profession or after specialising in a particular subject; these were driven by the new challenges that teaching offered.

All showed a strong enthusiasm for teaching, while acknowledging its stresses, hard work and emotional and temporal demands. They still found it exciting and intrinsically rewarding, greatly enjoyed working with young people, and had a strong vocational or moral commitment to their profession with a clear sense of professional identity.

These findings have implications for the recruitment of trainee teachers. The evidence reveals that personal qualities such as passion and enthusiasm both for their subject and for learning, combined with enjoyment of working with children or young people and moral commitment to support their learning and development, are all important. It suggests that such personal qualities, combined with good training, professional development opportunities, recognition and supportive work environments may be crucial to their future success in the classroom and in coping with the many complex demands placed on the profession.

Over half the sample (9) referred to particular teachers that had taught them when they were at school who had inspired them or motivated them to go on to become teachers themselves.

"I had a PE teacher who was really good fun. She just had a real passion for her subject and she really enjoyed teaching and you could tell she really enjoyed being with the students....... just the atmosphere of the classroom made you want to be there". (Female, Secondary, 0-5 YoE)

Interestingly, over a third (7) referred to teachers who taught them the same subject they went on to specialise in or teachers who had taught them in similar year levels and sector to the ones they were currently teaching. Nearly half (8) also cited inspirational colleagues who had fired their passion through their example at the schools where they had worked, including teachers, middle leaders and head teachers. This highlights the infectious role of inspiration via formal or informal mentors.

"At my last school I felt the head of department was quite inspirational, he had just a really lovely way with the kids, a really good rapport ...... I felt that that was sort of the bond that actually got the best out of the kids. So I aspired to be like him".(Female, Secondary, 11-15 YoE)

Other motivating examples noted included mentors during teacher training and teachers among their own families and friends. In two instances, however, interviewees noted the experience of a 'poor' teacher had spurred them to enter the profession to do better and make a difference to future students' experiences of learning.

"I probably wanted to teach this subject because my teacher was so uninspiring. And being good at it I found it easy, but there were lots of people that didn't find it easy, so my mission has always been to try to simplify the subject as much as possibles".(Female, Secondary, 6-10 YoE 
All participants viewed teaching as important for society and felt that inspiring teaching could make a meaningful difference to young people's learning and successful futures.

\section{Career aspirations, satisfaction, motivation and commitment}

Many in the sample had addition roles in middle and a few in senior leadership positions. Nonetheless, a large number (12) said they preferred to continue as classroom teachers, a position in which they felt comfortable and successful. Without exception all these teachers wanted to remain working inside the classroom with students, or in areas closely related to teaching and learning. A minority (6) also felt leadership positions would provide opportunities to have a greater impact on their schools in future. A tension was identified between their desire to remain in the classroom and career development. Finally, despite generally high levels of current satisfaction with their current schools, a few (4) were considering moving schools to further their experience and gain promotion.

Most (14) teachers indicated that their current motivation was high and they were sustaining their commitment and engagement, using phrases such as: "it's a vocation for some", "I love my job" and "I'm dedicated". Overall, primary teachers expressed higher levels of motivation than the secondary teachers, this may have reflected recent unpopular curriculum and examination changes particularly affecting secondary schools in England. Teachers were most satisfied with aspects of their jobs that involved contact with students. Although many were worried about external policies, only one teacher was now so disillusioned as to consider leaving the profession.

Teachers' wellbeing and motivation were affected by personal and professional circumstances, including work-life balance, adapting to new roles within their school, external pressures related to student and teacher assessment and curriculum changes, school support, student behaviour and interest, and personal and health events. Participants believed teaching is an extremely demanding profession with excessive workload. Difficulties in sustaining work-life balance were noted frequently, especially by female teachers.

Ultimately, the two key features of enthusiasm and the development of positive relationships with students seem to underpin these teachers' job satisfaction and motivation and their continued commitment to the profession despite such pressures and difficulties.

\section{Are inspiring teachers also more effective?}

When defining inspiring teaching, participants also touched on the relationship of this concept to others that are more commonly used to describe teachers and their practice, such as effective and outstanding teaching. Indeed, several teachers (3) strongly expressed the belief that being inspiring and being effective were related and mutually dependent aspects of teaching:

"I think to be inspiring as a teacher you have to be effective, you have to make sure that the kids are learning, and that they're enjoying being in your classroom" (Female, Secondary , 0$5 \mathrm{YoE})$.

Many of the features of inspiring practice raised by teachers and discussed above could also be seen in definitions of 'Outstanding' teaching as evident in external inspection criteria in use in England at the time (2013). Sir Michael Wilshaw, the Chief Inspector of Schools, highlighted features of good teaching in relation to children's responses and outcomes as follows: "children enjoyed their lessons, were engaged, were focused, learnt a great deal and made real progress...and in the best lessons (are) being inspired" (London Festival of Education, 2012). Here the inspectorate's view strongly links 
best practice to outcomes for children and the concept of 'inspiring', but without defining what inspiring entails.

However, one of the participants explicitly distinguished 'inspiring' from their understanding of Ofsted's definition of 'Outstanding' teaching by focussing strongly on the emotional component linked with the level of teachers' dedication and care for their students..

'An inspiring teacher isn't necessarily an 'Outstanding' teacher. I think that teachers do much more....they've really invested their time and they really care". (Male, Secondary, 0-5 YoE).

Both the quantitative and the qualitative observation findings identified much overlap between the features of effective teaching and the practices observed in these teachers' classes. There is a strong tradition of judgments of effective teaching based on studies of student outcomes and wider research evidence has identified features of teaching and classroom practice linked with greater effectiveness in fostering better student outcomes (Muijs \& Reynolds, 2005; Teddlie et al, 2006; Kington et al, 2014, Muijs et al. 2014).

Based on the observations (11 teachers were observed on two occasions, the remainder once), these teachers demonstrated many practices and behaviours typically associated with highly effective teaching including:

- Creating a positive, safe, and supportive climate for learning

- Managing behaviour, space, time, and resources efficiently and effectively

- Implementing clear instruction, including explicit and high expectations and objectives for learning

- Demonstrating good behaviour management skills and efficient use of learning time

- Skilful use of questioning and feedback to make lessons highly interactive and extend learning.

In addition, inspiring teachers were found to be:

- Using largely informal approaches to meet individual student needs

- Promoting high levels of student engagement and motivation through varied learning activities and arrangements

- Seeking ways to promote and honour student choice and input

- Using a wide variety of activities or approaches over the course of a lesson

- Showing high levels of commitment and care for students' learning and well being

- Developing and reinforcing positive relationships with students.

Although 'inspiring' is a looser concept with broader connotations and strong links with emotions, quantitative observation results indicate that teachers in this study were highly effective practitioners. Qualitative observation notes also supported this conclusion; with many examples documented in the full report (Sammons et al, 2014).

To use effective practices was not seen to constrain these teachers, or inhibit them from being inspiring. The combination of evidence implies that the two concepts are complementary, though some additional and important distinctive features were found that distinguish inspirational practice. Thus strengths as an effective practitioner may be a necessary foundation but not sufficient for inspirational practice.

\section{Strengths of inspiring teachers' effective practice}

Inspiring teachers scored highly in terms of all the various components and indicators in the ISTOF and QoT schedules, and there was relatively little variation in ratings among the 17 teachers 
observed, despite differences in sector and subject taught. Thus the teachers were found to be relatively homogeneous in these key features of their observed behaviour. They also scored more highly than samples of teachers in other published studies and evaluations that had used these two systematic observation schedules (Teddlie et al., 2006; van de Grift, 2007), suggesting they were indeed exemplary in terms of such characteristics of effectiveness.

Notable strengths in ratings on the ISTOF schedule included creating a positive Classroom climate, and Assessing and evaluating pupils' learning, Managing the behaviour in the classroom and providing Clear instruction. In line with these results, the teachers obtained consistently high scores on the QoT components Safe and orderly school climate, Effective classroom layout, Clear instruction and Effective classroom organization. Although still favourable, scores for adaption of teaching were somewhat lower for both instruments.

There were also several strengths in the Instructional skills dimension. Here the teachers showed high scores for providing 'sufficient wait time and response strategies to involve learners', 'giving assignments that stimulate active involvement', 'posing questions which encourage thinking and elicit feedback', and using a 'variety of instructional strategies'. In terms of the dimension Promoting active learning and developing metacognitive skills, the 17 teachers also showed strengths in indicators 'encouraging students to ask one another questions', giving them 'opportunities to correct their own work' and asking them to 'reflect on their own answers'.

While the quantitative schedules provided evidence regarding how far inspiring teachers demonstrated features of effective practice, the qualitative observations complemented and extended the quantitative findings. The various themes identified highlight aspects of teachers' practice that offer further insight into what defines 'inspiring' over and above effective teaching.

\section{'Inspiring' approaches to effective practice}

Based on field notes, teachers in the sample demonstrated good use of time, well-defined lesson components (e.g. introduction and closure) and smooth transitions; they also engaged in frequent clarification of task instructions and lesson objectives. What defined these teachers' practice over and above the basic categories included in observation schedule items, however, was that most used strategies to actively engage students in lesson introductions and closures as well as through clarification of objectives and task instructions. This was often accomplished by using some combination of novel or exciting activities, eliciting explanations from students frequently, and checking in with individuals to make sure they were on track and understanding.

Few instances of formal differentiation were observed. Instead, most teachers made frequent use of informal approaches to meet students' individual needs, such as circulating to provide individual support during independent or small-group work, or using additional adults in the room to support struggling individuals or groups.

Teachers used a variety of strategies to involve and interest students. All made connections between lesson content and examination standards and performance, students' daily lives beyond the classroom, popular culture, or novel or exciting topical events likely to engage students' interest and attention; teachers commonly engaged students actively in establishing these links through questioning and eliciting student ideas. Many lessons were also characterised by an emphasis on variety of activities, configurations or groupings of students, materials, and modes of instruction. Further, teachers commonly prioritised student input and choice, allowing students to choose between activities, to select their own partners or groups, or (particularly for older-age primary and secondary students) to select between levels of difficulty or define their own targets. Finally, a few 
teachers made use of technology to involve and interest students in innovative and unusual ways, such as using iPads for interactive tasks. The vast majority of teachers presented parts of their lessons using Smart boards, but only in some cases did students interact with the board/other technology tools. Nonetheless, using technology in unusual ways was not a major feature of inspiring teachers' practice.

The inspiring teachers' classes were highly interactive. Teachers laid great emphasis on questioning and feedback to support learning. This was a key way to promote high levels of student engagement and motivation. All teachers used positive feedback, both general and specific, with groups of students as well as individuals; this appeared to create a generally positive atmosphere. Further, all teachers used at least some open-ended questions to engage students as participants in their own learning. This included both academically-oriented questions that encouraged students to make connections beyond the immediate topic or to explain their thinking, and questions designed to help students to reflect on their own learning or on the work and ideas of their peers. It was especially common for students to be asked to engage explicitly with metacognitive types of questions in secondary lessons, while primary teachers usually invited students to reflect and offer feedback in simpler terms. Questioning was generally designed to make lessons and interactions as inclusive as possible.

In terms of classroom management, there was clear evidence of well-understood routines enabling classes to work smoothly. Students had internalised these - this fostered independence and selfregulation, and helped maximise learning time. This was visible in students' routinized behaviour at the beginning and end of a lesson, handling of resources and materials with efficiency, clearly established rules and consequences, and ways of communicating. No major disruptions were observed in any of the lessons, and in responding to minor disruptions, most teachers either selectively ignored problematic behaviours to avoid exacerbating problems or addressed them swiftly. They did not use negative role-confirming remarks, favouring gentle reminders and quick comments with an emphasis on promoting productive use of time. Teachers typically demonstrated a positive rapport with students that facilitated their ability to prevent or minimise disruption. Interestingly, many teachers in the sample involved students actively in classroom management; in many classrooms, students were given responsibility for resources and classroom space (particularly distributing and clearing materials) and leadership roles (including roles assigned to students exhibiting challenging behaviours to occupy them constructively), and an established expectation to help one another.

While structured observation schedules were able to capture evidence of group-work and independent work in lessons in terms of occurrence and frequency, the qualitative field notes highlighted richer detail about the interactions between students and norms around productive and academic work and communication in lessons. Many of the activities observed required students (sometimes pairs or groups) to work independently. Quite a few lessons also included time for students to reflect and give feedback on the work of peers; teachers were often more directly engaged in this process than in facilitating other types of paired or group work, guiding students' conversations toward productive and constructive engagement. The independent behaviours and communication skills exhibited by students suggested that teachers had encouraged these over time, and this was corroborated by interview comments. They designed lessons to provide opportunities for student independence and established expectations for best practices with regard to collaborative work, emphasising communication skills.

\section{Emotional dimensions of 'inspiring' practice}

As noted in interviews, all teachers indicated they laid a strong emphasis on positive relationships with students, and the observation data strongly support these claims. There was a clear emotional dimension of relationships and interactions in observed lessons not picked up by structured 
observation schedule items but referenced in higher-inference comments in field notes, suggesting that these features are closely linked to their inspiring practice.

Relationships between teachers and students were characterized most often in field notes as 'relaxed', 'warm' and 'friendly'. Teachers treated students as individuals; they were sensitive to students' interests, ethnic and language backgrounds, and behavioural and special educational needs. The majority showed keen awareness of students' lives and interests beyond the classroom as well as students' individual learning needs and targets both explicitly (by directly discussing their learning or behaviour targets) and implicitly (by offering extra support to a struggling student or extension opportunities to students with stronger skills).

Enthusiasm and engagement were prominently featured in the field notes. Students appeared to like their teachers, while teachers were generally seen to show enthusiasm and enjoyment in their dealings with students. It was clear in all lessons that teachers were respected, generally well liked and clearly in charge of their classes to support all students 'learning. There was evidence of engagement demonstrated by much task-focused communication between students as well as with the teachers, and lessons were highly interactive with opportunities for students to work together collaboratively.

Positive and supportive relationships were evident in observed lessons. Many teachers used humour at some point during the lesson, often not by actually telling jokes but willing to laugh with students or say unexpected things to surprise and amuse. Teachers created 'safe spaces' for students to contribute with confidence and also to make mistakes, as reflected in feedback given when students gave erroneous answers. They expressed high expectations for their students, usually through some combination of formative feedback, clearly-articulated expectations that students could complete challenging tasks, and targets expressly designed to move each student's learning on.

\section{Discussion and Conclusions}

The Inspiring Teachers study sought to enhance current understandings of what is meant by inspiring practice, and to explore the characteristics and views of teachers identified by their schools as notable exemplars. Each source of evidence offered rich information and some unique contributions, but there are strong overlaps that add to the robustness of the conclusions. In this paper, key findings from interviews and observations have been explored in more detail to investigate their relevance to professional development and the creation of learning communities.

Taken together, the integration and synthesis of different perspectives (teachers' voices and direct observations) yields rich insights into the core features of inspiring practice. These include:

- positive relationships

- good classroom/behaviour management

- positive and supportive climate

- formative feedback

- high quality learning experiences

- enjoyment (for teachers and students)

- student engagement and motivation.

It is argued that such core features provide valuable foci for professional development using teacher collaboration (within or across schools), peer observations and formative feedback to support reflection and mutual learning. 
Interestingly, few of the inspirational teachers made great or unusual use of modern technology in their practice, though they were keen to master and apply new approaches where appropriate. They were not at the vanguard of cutting edge developments, although they all recognised the importance of technology. Developing their IT skills was commonly cited as one of the key areas for future CPD but they saw it as a tool, not a replacement for the quality of engagement between teachers and students. This accords with findings from PISA, for which countries where students made more use of computers at school have shown a decline in reading performance between 2000 and 2012. The OECD stresses the continued need for schools to ensure students to develop a good grounding in traditional outcomes of literacy and numeracy to facilitate their future participation in the hyper-connected digitised world of the 21st century (OECD, 2015).

Some argue that traditional approaches are outdated, reflecting a 20th century 'factory' approach to schooling (e.g. Hannon, Christensen and Horn, 2008). The evidence here does not fully support such claims, as it was strengths in features of highly effective classroom practice (evidence from the classroom observations) combined with confidence, careful planning and variety of activities that introduced fun, surprises and excitement into the learning experience for students in these teachers' classes. Being highly effective was not a barrier to being inspirational, and many of the sample felt these two were mutually supportive in ensuring and sustaining their success in the classroom.

These teachers showed flexibility and moral purpose. They were successful in creating a supportive emotional climate in lessons, demonstrating the care, commitment and enthusiasm that seemed particularly important in promoting better outcomes for students in terms of enhancing their engagement, enjoyment and learning. These exemplary teachers created classrooms environments where students felt valued and wanted to be.

Inspiring practice does not develop or occur in isolation. Teacher interviews suggest that their practice was contextualised in supportive school cultures, and many pointed to the roles of colleagues in their past or current schools who had inspired or supported them. Inspiration, as the origins of the word imply, does seem to be infectious and have long term consequences for individuals. Many teachers commented on inspirational teachers from their own past schooling when young, or had an inspiring example in their training or earlier career from a mentor or colleague who had motivated them and provided a model to emulate. A few specifically noted negative examples as a spur, highlighting their own moral purpose and illustrating why they wanted to be different to counter poor practice through their own examples.

In terms of the literature reviewed, it is clear that personal qualities or traits such as enthusiasm, passion for subject, learning and a strong liking for children and young people are key motivators for these successful teachers. They are closely linked with job satisfaction and help to retain motivation and commitment, despite the realistic appreciation of externally driven pressures and challenges in the wider educational context in which these teachers worked. This aligns with arguments by Day (2004) that those with a passion for teaching are committed, enthusiastic and both intellectually and emotionally energetic in their work with students, making them well placed to be leaders of learning in their schools.

As noted in the introduction, the project was a collaborative venture instigated by head teachers. The fact that this research was motivated by head teachers' interest in understanding and promoting inspiring teaching in their schools indicates a key feature of enquiry-minded leadership with an interest in promoting professional learning communities between and across CST schools, which in turn facilitates collaborative and reflective enquiry (Stoll, Bolam, \& Collarbone, 2002). Further, it exemplifies an ambitious attempt to capitalise on the expertise and experience in the schools themselves to inform professional development based on teachers' individual and shared experience and practice (Hargreaves \& Fullan, 2012). This may also happen less formally, with core elements of inspiring practice becoming absorbed into the culture of practice in and across schools 
based on exemplars and shared meanings emerging from this research. It may help to reduce 'within school variation' by raising quality of teaching and learning through mutual learning.

According to the research manager at CfBT Education Trust, the results of the Inspiring Teachers research has supported various improvement activities.

'It's been instrumental in inspiring or influencing a range of activities and been of interest to our Schools Partnership Programme (SPP) and CST.

The report continues to influence our professional development thinking for teachers. We are currently refining a course developed for teachers that builds on concepts that the research revealed as integral to being inspirational............ Elements of the research concerning collaboration and reflection also pervade the thinking underpinning our work with CST to support research engagement and the ongoing work of the SPP ...... this research has been instrumental in evidencing the theoretical concepts that bind SPP.'

These comments fit well with both constructivist and socio-cultural theoretical perspectives on learning in working with teachers and schools. Lancer (2015), discussing the meaning of 'quality professional learning' for school improvement, argued that constructivist approaches view learning $s$ an active participatory mental process of constructing new knowledge extending existing cognitive schemas through new experiences. Socio-cultural perspectives see learning as both 'cognitive and social ......... constructing new knowledge in a context of active engagement with others' (Lancer, 2015:645). CfBT commissioned the research to create new and relevant evidence to inform, stimulate and (hopefully) inspire its teachers and promote their active engagement with the findings through reflection and active collaboration opportunities, combined with tailored resources and engagement with external 'research leads', to foster the development of professional learning communities.

This research and the way it is being used shows a strong interest in the conception of schools as learning organisations that promote knowledge creation with the aim of facilitating continuous improvement. This links with the concept of schools becoming self-renewing organisations characterised by a professional culture of interdependence (Southworth, 2000).

As Hargreaves and Fullan (2012) point out, sharing practice can be "loose, unfocused, and inwardlooking" (p.112); on the other hand, exemplary practitioners are well-situated to take on active roles in collaborative professional development efforts, which Muijs and Harris (2006) suggest bolsters the development of teacher leadership in schools. Findings from this study thus have the potential to inform foci for professional learning communities in and across schools to promote and facilitate inspiring teaching, as well as supporting and extending effective practice with the eventual goal of achieving "strong and measurable improvements in students' learning", encouraging a proactive and outward rather than an inward looking stance (Hargreaves, 2003, p.3).

While many education systems are exploring the use of narrow value added approaches for teacher evaluation and accountability, such approaches on their own cannot help teachers gain insight into what makes a difference to student learning or progress (van der Lans, van de Grift $\&$ van Veen, 2015). Rather a range of evidence and perspectives is needed emphasising formative practice. By focussing on the qualities and practices of inspiring teachers and building on their strengths in working with colleagues, this research sought to inform the cultivation of professional learning communities that support formative practice to enhance the quality of student and teacher learning 
and teachers' professional development, while fostering their motivation and commitment to the profession.

\section{References}

Advanced Analytics. (2011). AgreeStat.

Blake, J. (2006). Burying literary treasure: Developing inspirational approaches to $A$ level literature. English Drama Media (NATE), (5), 21-26.

Bowman, R. F. (2007). How Can Students Be Motivated: A Misplaced Question? The Clearing House: A Journal of Educational Strategies, Issues and Ideas, 81(2), 81-86.

Bryan, R. R., Glynn, S. M., \& Kittleson, J. M. (2011). Motivation, achievement, and advanced placement intent of high school students learning science. Science Education, 95(6), 1049-1065.

Bryson, C., \& Hand, L. (2007). The role of engagement in inspiring teaching and learning. Innovations in Education and Teaching International, 44(4), 349-362.

Burke, R. W., \& Nierenberg, I. (1998). In search of the inspirational in teachers and teaching. Journal for a Just and Caring Education, 4(3), 336-54.

Christensen, C.M., Horn, M.B., \& Johnson, C.W., (2008). Disrupting class; How disruptive innovation will change the way the world learns. New York: McGraw Hill.

Collins, P. M. (2006). Inspiring high student performance through an integrated philosophy of education. Performance Improvement, 45(8), 31-33.

Day, C. (2004) A Passion for Teaching. London and New York: Routledge Falmer.

Day, C., Sammons, P., Kington, A., Regan, E., Gunraj, J., \& Towle, J. (2007). Effective Classroom Practice: A mixed methods study of influences and outcomes: Interim report submitted to the ESRC. Swindon.

Department for Education. (2013). Teachers'standards. London.

Erwin, J. C. (2010). Inspiring the Best in Students. Alexandria: ASCD.

Gilson, C., Roberts, K., Pratt, M. \& Weymes, E. (2002) Peak Performance: Business Lessons from the World's Top Sports Organisations, HarperCollins.

Hargreaves, A. (2003). Teaching in the knowledge society : education in the age of insecurity. Buckingham: Open University Press. 
Hargreaves, A., \& Fullan, M. (2012). Professional capital : transforming teaching in every school. New York; London: Teachers College Press.

Hobbs, L. (2012). Examining the aesthetic dimensions of teaching: Relationships between teacher knowledge, identity and passion. Teaching and Teacher Education, 28(5), 718727.

IBM Corp. (2012). IBM SPSS Statistics for Windows. Armonk, NY: IBM Corp.

Kington, A., Sammons, P., Brown, E., Regan, E., Ko, J., \& Buckler, S. (2014). Effective classroom practice. Maidenhead: Open University Press.

Lancer, J. (2015)b The meaning of quality professional learning for school improvement: articulating a coherent vision rooted in a theoretical perspective', School Effectiveness and School Improvement, 26(4) 639-667.

What makes an Ofsted 'outstanding' lesson? (2013, July 4). Retrieved from http://www.headteacher-update.com/best-practice-article/what-makes-an-ofsted outstanding-lesson/66775 (Accessed November 9, 2012).

McGuey, G., \& Moore, L. (2007). The inspirational teacher. Larchmont, NY: Eye On Education.

Muijs, D., \& Harris, A. (2006). Teacher led school improvement: Teacher leadership in the UK. Teaching and Teacher Education, 22(8), 961-972.

Muijs, D., Kyriakides, L., van der Werf, G., Creemers, B., Timperley, H., \& Earl, L. (2014). State of the art - teacher effectiveness and professional learning. School Effectiveness and School Improvement, 25(2), 231-256.

Muijs, D., \& Reynolds, D. (2005). Effective teaching : evidence and practice. London; Thousand Oaks, Calif.: SAGE Publications.

Office for Standards in Education. (2011). The forest school; a thrilling and inspiring environment for pre school children: Fleetwood's Charity Pre-School Group. London.

Organization for Economic Cooperation and Development. (2013). Innovative Learning Environments. Paris.

President's Council of Advisors on Science and Technology. (2010). Prepare and Inspire: K-12 Science, Technology, Engineering, and Math (STEM) Education for America's Future. Washington, D.C.

QSR International. (2012). NVivo qualitative data analysis software.

Richards, J. (2004). Enchanting Teachers among Us. Childhood Education, 80(3), 128-133. 
Sammons, P., Day, C., Kington, A., Gu, Q., Stobart, G., \& Smees, R. (2007). Exploring variations in teachers' work, lives and their effects on pupils: key findings and implications from a longitudinal mixed-method study. British Educational Research Journal, 33(5), 681-701.

Sammons, P., Kington, A., Lindorff-Vijayendran, A., \& Ortega, L. (2014). Inspiring Teachers: Perspectives and Practices, Reading: CfBT.

Santolini, S. (2009). Why we teach: Autobiographies of traditionally and alternatively certified pre-service social studies teachers. The Qualitative Report, 14(3), 478-488.

Southworth, G. (2000) How primary schools learn, Research Papers in Education, 15(3) 275291.

Stoll, L., Bolam, R., \& Collarbone, P. (2002). Leading for change: Building capacity for learning. In K. Leithwood \& P. Hallinger (Eds.), Leading for change: Building capacity for learning. Kluwer: Dordrecht.

Teddlie, C., Creemers, B., Kyriakides, L., Muijs, D., \& Yu, F. (2006). The international system for Teacher Observation and Feedback: Evolution of an international study of teacher effectiveness constructs 1. Educational Research and Evaluation, 12(6), 561-582.

Van de Grift, W. (2007). Quality of teaching in four European countries: a review of the literature and application of an assessment instrument. Educational Research, 49(2), 127-152.

van der Lans, R., van de Grift, W., \& van Veen, K. (2015) Developing a Teacher Evaluation Instrument to Provide Formative Feedback Using Student Ratings of Teaching Acts, Edycational Measurement: Issues and Practices, 34 (3) 18-27.

Van der Zee, T. (2011). Inspiration: a thought-provoking concept for RE teachers. British Journal of Religious Education, 34(1), 21-34. 